\title{
Experience of a Single Center in the Diagnosis and Classification of Cases of Left Ventricular Noncompaction
}

\author{
Roberta Martinoli ${ }^{1}$, Patrizia Saccucci ${ }^{*}$, Federica Papetti ${ }^{2}$, Alessandro Dofcaci ${ }^{2}$, \\ Stefano Piccirilli ${ }^{3}$, Ilaria Sansoni ${ }^{4}$, Francesca Ianniello5, Federica Ferrante ${ }^{6}$, Maria Banci ${ }^{2}$ \\ ${ }^{1}$ Department of Biomedicine and Prevention, University of Rome "Tor Vergata", Rome, Italy \\ ${ }^{2}$ Operating Unit of Cardiology, Valmontone Hospital, Rome, Italy \\ ${ }^{3}$ Department of Cardiology, University of Rome "Tor Vergata", Rome, Italy \\ ${ }^{4}$ Department of Imaging Diagnostic, University Campus Biomedical, Rome, Italy \\ ${ }^{5}$ Operating Unit of Gynecology, Valmontone Hospital, Rome, Italy \\ ${ }^{6}$ Operating Unit of Neurology, Valmontone Hospital, Rome, Italy \\ Email: saccucci@med.uniroma2.it
}

Received 26 February 2015; accepted 6 April 2015; published 10 April 2015

Copyright (C) 2015 by authors and Scientific Research Publishing Inc.

This work is licensed under the Creative Commons Attribution International License (CC BY).

http://creativecommons.org/licenses/by/4.0/

(c) (i) Open Access

\begin{abstract}
Objectives: To analyse the clinical profile of consecutive cases of Left Ventricular Non Compaction (LVNC) with particular interest in non-compacted segments valuation. Methods: There were 18,000 patients seen from 2007 to 2010 , with a complete evaluation including family history and personal cardiac history, clinical examination and electrocardiography. Diagnosis was based on three published definitions. Results: The diagnosis of LVNC was placed in $1.4 \%$ of cases. Clinical and echocardiographic data for the $\mathbf{2 5 0}$ cases of LVNC are presented. Trabecular meshwork was observed predominantly at the apex $(91.6 \%)$, in the lateral and inferior wall $(40.4 \%$ and $38.0 \%$ respectively), and less frequently in the posterior and anterior wall (21.6\% and $9.2 \%$ respectively). Conclusions: This study suggests that LVNC is a form of cardiomyopathy with higher prevalence and relatively better prognosis than previously reported.
\end{abstract}

\section{Keywords}

Cardiomyopathy, Endocardial Morphogenesis, Isolated Left Ventricular Noncompaction, Heart Failure, Echocardiography

\footnotetext{
*Corresponding author.
}

How to cite this paper: Martinoli, R., et al. (2015) Experience of a Single Center in the Diagnosis and Classification of Cases of Left Ventricular Noncompaction. International Journal of Clinical Medicine, 6, 235-248. 


\section{Introduction}

Non-compaction of the left ventricle (LVNC) is a disorder of endomyocardial morphogenesis that results in multiple trabeculations in the left ventricular myocardium and intratrabecular recesses that communicate with the ventricular cavity rather than the coronary circulation [1].

This disorder, becoming widely known in the last 15 years [2], is postulated to be caused by intrauterine arrest of compaction of the myocardial fibres and meshwork, an important process in myocardial development which takes place between the fifth and the eighth weeks of gestation [3].

The current literature suggests that LVNC in adults is rare, and associated with a poor diagnosis [2]-[5]. The clinical presentations varied ranging from asymptomatic patients to patients who develop heart failure, ventricular arrhythmias, embolic events and sudden cardiac death [6].

Given that the disorder is present at birth and that several studies have reported asymptomatic familial disease in some patients, we hypothesized that there is a long pre-clinical phase of disease and that the published prognosis figures are unrepresentative of the true natural history of the disease.

\section{Material and Methods}

The patients, seen in the Valmontone Hospital's Cardiology Clinic from 2007 to 2010, were evaluated with a complete history, physical exam and echocardiography. The study population includes 18,000 subjects $(10,467$ men and 7533 women). Patients or their parents, in case of $<18$ years, gave consent for participation in the study that was approved by the IRB.

\subsection{Echocardiography}

All patients underwent a complete two-dimensional and Doppler echocardiography. Echocardiograms were evaluated by two independent investigators blinded to individual clinical and demographic details. Only cases identified as LVNC by both observers were considered as positive.

The diagnosis of LVNC was placed in the presence of criteria described by Chin et al. (1990) [1], Jenni et al. (2001) [7] [8], Stöllberger et al. (2001) [9].

1. The Chin et al. criteria focus on trabeculae at the left ventricular apex on the parasternal long-axis, subcostal and apical views, and on left ventricular free-wall thickness measured at end-diastole. A ratio of $\mathrm{X} / \mathrm{Y} \leq 0.5$, where $\mathrm{X}$ represents the distance from the epicardial surface to the trough of the trabecular recess and $\mathrm{Y}$ the distance from the epicardial surface to peak of trabeculation, is suggestive of LVNC.

2. The Jenni et al. criteria are founded on the presence of a two-layer structure with a thin compacted epicardial layer (C) and a thicker non-compacted endocardial layer (N) measured at end-systole from the parasternal short-axis and apical approaches. Here LVNC is defined by a ratio of N/C $>2$ in adults or more than 1.4 in children.

3. For Stöllberger et al. the presence of more than three trabeculations protruding from the left ventricular wall, apical to papillary muscles and visible in a single image plane constitute the echocardiographic hallmarks of LVNC. These trabeculations must move synchronously with the myocardium and must have its same echogenicity. The intertrabecular spaces must be perfused from the ventricular cavity and visualized on colour Doppler imaging.

Left ventricular volume and ejection fraction (EF) were calculated using the modified Simpson's rule, by tracing the endocardial border in two-chamber view and four-chamber view. End diastole was defined as the frame in the cardiac cycle in which the cardiac dimension is largest and end systole was best defined as the time in the cardiac cycle in which the cardiac dimension is smallest [10].

\subsection{Statistical Analysis}

Results are presented as mean values \pm standard deviation or frequency expressed as a percentage.

\section{Results}

\subsection{Patient Population}

This observational study comprised 18,000 patients consecutively identified at the Valmontone Hospital's Car- 
diology Clinic over a 3-year period.

As shown in Table 1, the main aetiologies of heart failure were coronary artery disease (44.5\%), hypertensive heart disease (23.4\%). Less represented were Dilated Cardiomyopathy (10.2\%), Valvular Disease (9.2\%), Hypertrophic Cardiomyopathy (8.1\%) and Congestive Heart Failure (2.5\%). As less frequent causes, over the LVNC, appeared Restrictive Cardiomyopathy (0.1\%), Arrhythmogenic Right Ventricular Dysplasia/Cardiomyopathy (0.1) and Neuromuscular Diseases (0.2\%). Other causes (0.3\%) included diabetes, hyperthyroidism, hypothyroidism, hemochromatosis and amyloidosis.

250 out the 18,000 patients satisfied at least one of the three most widely used echocardiographic criteria for LVNC (Chin et al., Jenni et al., Stöllberger et al.); 52 subjects fulfilled at the same time all three criteria.

Part of the study-population was subjected to echocardiography having been sent by general practitioners and in this case the diagnosis of LVNC was entirely incidental. In other cases echocardiography was proposed as part of the diagnostic in patients with CAD or hypertension. A portion of our sample is made up of professional athletes sent by sport physicians of the area to our Operating Unit of Cardiology for an echocardiographic evaluation in order to clarify the nature of physical examination and/or electrocardiogram abnormalities. Finally a fraction of our sample is made up of first-degree relatives of patients who had been diagnosed with LVNC. Screening of families has allowed us to verify the phenotypic heterogeneity of this condition. Within the same family group it is possible to find isolated cases of DCM and isolated cases of LVNC. Among the patients with LVNC the severity of clinical presentation is highly variable, as if there was a different penetrance of the defect genetically expressed.

Of the 250 patients with LVNC, 154 were man and 96 women (male percentage 61.6\%). The median age at diagnosis was 35 years with an age range from 0 to 88 years ( $\mathrm{SD} \pm 21.0)$.

Patients were divided into three groups: 18 years of age or younger, 19 - 50 years of age and more than 50 years of age. Each group was further divided by gender. It was thus possible to identify six subpopulations: the paediatric feminine subpopulation (21 subjects); the adult feminine subpopulation aged under 50 years (45 subjects); the adult feminine subpopulation aged over 50 years (30 subjects); the paediatric masculine subpopulation (74 subjects); the adult masculine subpopulation aged under 50 years (43 subjects); the adult masculine subpopulation aged over 50 years (37 subjects).

\subsection{Clinical Presentation}

At the time of diagnosis 119 (47.5\%) of the 250 subjects with LVNC were asymptomatic. Disorders that were

Table 1. Etiology of heart failure on 18,000 consecutive patients seen in our center over a period of three years.

\begin{tabular}{cccc}
\hline CAD & $\begin{array}{c}\text { Population } \\
(\mathbf{n}=\mathbf{1 8 , 0 0 0})\end{array}$ & $\begin{array}{c}\text { Male } \\
(\mathbf{n}=\mathbf{1 0 , 4 6 7 )}\end{array}$ & $\begin{array}{c}\text { Female } \\
(\mathbf{n}=\mathbf{7 5 3 3})\end{array}$ \\
DCM & $8010(44.5)$ & $4914(27.3)$ & $3096(17.2)$ \\
Valvular Disease & $1838(10.2)$ & $1165(6.5)$ & $673(3.7)$ \\
Congestive Heart Failure & $1656(9.2)$ & $720(4.0)$ & $936(5.2)$ \\
LVNC & $450(2.5)$ & $216(1.2)$ & $234(1.3)$ \\
Hypertensive Heart Disease & $\mathbf{2 5 0 ( 1 . 4 )}$ & $\mathbf{1 5 4 ( \mathbf { 0 . 9 } )}$ & $\mathbf{9 6 ( \mathbf { 0 . 5 } )}$ \\
HCM & $4212(23.4)$ & $2268(12.6)$ & $1944(10.8)$ \\
RCM & $1458(8.1)$ & $972(5.4)$ & $486(2.7)$ \\
ARVD/CM & $18(0.1)$ & $4(0.02)$ & $14(0.08)$ \\
Neuromuscular Diseases & $18(0.1)$ & $18(0.1)$ & $0(0.0)$ \\
Other Causes & $36(0.2)$ & $18(0.1)$ & $18(0.1)$ \\
\hline
\end{tabular}

The values given in parentheses are percentages. CAD, Coronary Artery Disease; DCM, Dilated CardioMyopathy; LVNC, Left Ventricular Non Compaction; HCM, Hypertrophic CardioMyopathy; RCM, Restrective CardioMyopathy; ARVD/CM, Arrhythmogenic Right Ventricular Dysplasia/ CardioMyopathy. 
more often reported by symptomatic subjects were precordialgia, wheezing, palpitations and tachycardia. There were no abnormal blood parameters except for blood glucose abnormalities and dyslipidemia in older patients.

Even with respect to the general population, neuromuscular abnormalities were present in $14.4 \%$ of cases. Dysmorphic features were obvious in $40.0 \%$ of the patients. Familial occurrence of LVNC was observed in $14.4 \%$ of the cases (see Table 2).

In particular, neuromuscular disorders were diagnosed in $24.0 \%$ of the paediatric feminine subpopulation (5 subjects out of 21); in $11.2 \%$ of the adult feminine subpopulation aged under 50 years ( 5 subjects out of 45 ); in $0.0 \%$ of the adult feminine subpopulation aged over 50 years ( 0 subjects out of 30); in 20.3\% of the paediatric masculine subpopulation (15 subjects out of 74 ); in $23.3 \%$ of the adult masculine subpopulation aged under 50 years (10 subjects out of 43 ); in $2.7 \%$ of the adult masculine subpopulation aged over 50 years ( 1 subjects out of 37).

Facial abnormalities were observed in $43.0 \%$ of the paediatric feminine subpopulation (9 subjects out of 21); in $13.4 \%$ of the adult feminine subpopulation aged under 50 years (6 subjects out of 45 ); in $6.7 \%$ of the adult feminine subpopulation aged over 50 years (2 subjects out of 30 ); in $68.9 \%$ of the paediatric masculine subpopulation (51 subjects out of 74); in $60.5 \%$ of the adult masculine subpopulation aged under 50 years (26 subjects out of 43); in $16.2 \%$ of the adult masculine subpopulation aged over 50 years (6 subjects out of 37) (see Table 3).

The electrocardiographic abnormalities were observed in $80.8 \%$ of the sample. Left ventricular systolic dys-

Table 2. Demographic and clinical characteristics of patients with LVNC (N, 250).

\begin{tabular}{cccc}
\hline Male, \% & 61.6 & QRS abnormalities & 9.6 \\
\hline Median age at diagnosis, y & 30.0 & Left bundle branch block & 4.4 \\
Age range, y & $0-88$ & Atrial fibrillation & 0.8 \\
Facial dysmorphia, \% & 40.0 & Right bundle branch block & 0.4 \\
Familiarity, \% & 14.4 & Wolff-parkinson-white syndrome & 0.4 \\
Non compacted areas & $\%$ & Left ventricular dysfunction, \% & 36.8 \\
Apex & 91.6 & Congestive heart failure, \% & 7.6 \\
Inferior wall & 38.0 & Systemic embolism, \% & 3.2 \\
Lateral wall & 40.4 & Pulmonary embolism, \% & 2.4 \\
ECG abnormalities, \% & $\mathbf{8 0 . 8}$ & Ventricular thrombi, \% & 1.2 \\
T wave abnormalities & 61.2 & Heart transplant, \% & 0.4 \\
Arrhythmias & 59.6 & Neuromuscular disorders, \% & 14.4 \\
Pathological P waves & 42.4 & Deaths, \% & 0.4 \\
\hline Ventricular tachycardia/premature beats & 15.2 & Sudden cardiac death, \% & 0.0 \\
\hline
\end{tabular}

Table 3. Presence of facial abnormalities in the study population matched for gender and age.

\begin{tabular}{|c|c|c|}
\hline & $\mathbf{N}$ & Facial abnormalities (\%) \\
\hline \multirow[b]{2}{*}{ Paediatric subpopulation } & 9 subjects out of $21 q$ & $43.0 \%$ \\
\hline & 51 subjects out of $74 \delta$ & $68.9 \%$ \\
\hline \multirow{2}{*}{$\begin{array}{l}\text { Adult subpopulation } \\
\leq 50 \text { years }\end{array}$} & 6 subjects out of $45+$ & $13.4 \%$ \\
\hline & 26 subjects out of $43 \hat{\jmath}$ & $60.7 \%$ \\
\hline \multirow{2}{*}{$\begin{array}{l}\text { Adult subpopulation } \\
\leq 50 \text { years }\end{array}$} & 2 subjects out of $30+$ & $6.7 \%$ \\
\hline & 6 subjects out of $37 \hat{\jmath}$ & $16.2 \%$ \\
\hline
\end{tabular}


function is among the most common clinical presentations (36.8\%), followed by congestive heart failure (7.6\%) (see Table 2). With respect to this latter condition there is a significant difference between the observed data and that reported in the literature ( $7.6 \%$ versus $57.4 \%$ as a mean value of the studies conducted by Chin et al., Ritter et al., Ichida et al., Oechslin et al. and Stöllberger et al.) [1]-[4] [11].

Less common presentations included systemic embolism (3.2\%), pulmonary embolism (2.4\%), ventricular thrombi (1.2\%) and atrial fibrillation (0.8\%). One patient underwent cardiac transplantation and died in 1 month after surgery (see Table 2).

Body Mass Index, calculating by the Quetelet formula [Weight $\left.(\mathrm{kg}) / \mathrm{Height}^{2}\left(\mathrm{~m}^{2}\right)\right]$ [12], was progressively increasing with age: it was near to lower limit of the normal range in paediatric groups but it tended to remain within the normal range (18 - 25) even among adults. More specifically, the BMI was equal to $18.2 \pm 1.7$ in the paediatric feminine subpopulation, to $19.7 \pm 1.5$ in the adult feminine subpopulation aged under 50 years, to $23.3 \pm 2.6$ in the adult feminine subpopulation aged over 50 years and to $19.2 \pm 1.8$ in the paediatric masculine subpopulation, $22.4 \pm 1.6$ in the adult masculine subpopulation aged under 50 years, $23.7 \pm 2.5$ in the adult masculine subpopulation aged over 50 years.

According to the 2007 ESH-ESC guidelines for the management of arterial hypertension [13], 12.8\% of the subjects were hypertensive. More specifically, it was hypertensive $4.4 \%$ of the adult feminine subpopulation aged under 50 years (2 subjects out of 45), 23.3\% of the adult feminine subpopulation aged over 50 years (7 subjects out of 30), 23.3\% of the adult masculine subpopulation aged under 50 years (10 subjects out of 43 ) and $37.8 \%$ of the adult masculine subpopulation aged over 50 years (14 subjects out of 37). Most patients had grade 1 hypertension (140 - $90 \mathrm{mmHg}$ ), while two men under 50 years and two over 50 years were suffering from Grade 2 hypertension (160 - $100 \mathrm{mmHg}$ ).

\subsection{Two-Dimensional Echocardiography}

Regard to the general population, trabecular meshwork was observed predominantly at the apex on two-dimensional echocardiography (91.6\%). Characteristic noncompaction morphology has also been found in the lateral and inferior wall (42.2\% and 34.8\% respectively) and less frequently in the posterior and anterior wall (21.6\% and $9.2 \%$ respectively) (see Figures 1-7).

Depressed left ventricular systolic function was clinically overt in 92 patients on 250 (36.8\%); in 3 patients it was only systolic (1.2\%); in 63 patients it was only diastolic (25.2\%); in 26 patients it was both systolic and diastolic (10.4\%).

As expected, the EF of the left ventricle obtained by the modified Simpson's rule [11] was higher in the two

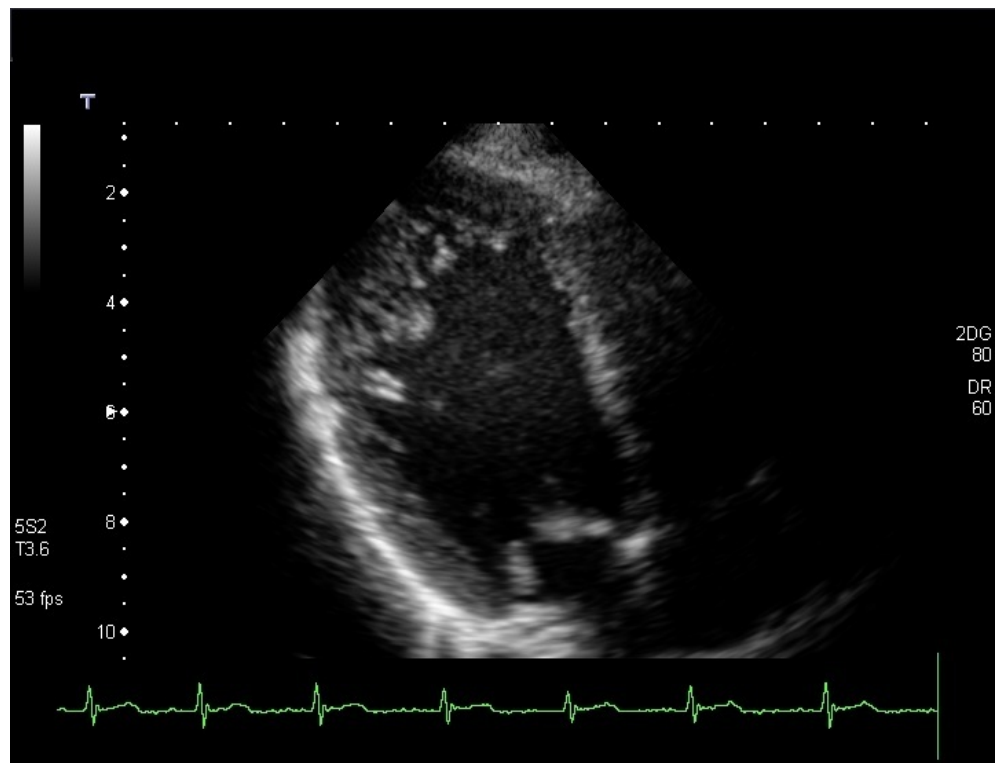

Figure 1. Transthoracic echocardiography, parasternal long axis, four-chamber view. 


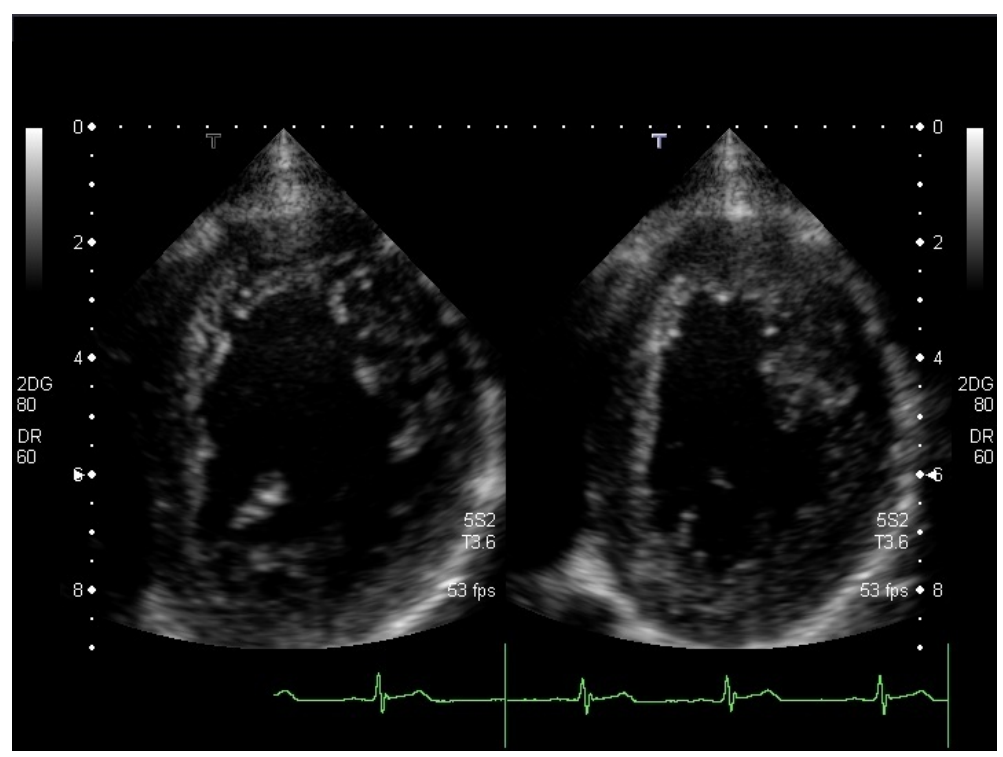

Figure 2. Four-chamber long axis view, an aspect of the left ventricle during diastole and systole.

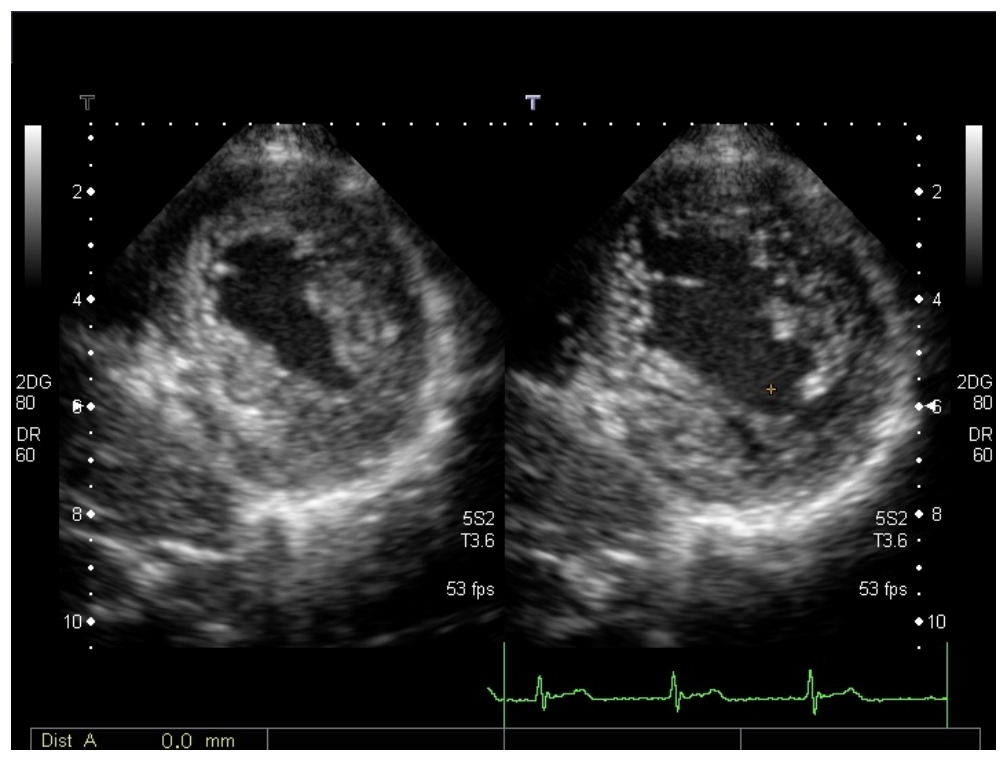

Figure 3. Apical medium during diastole and systole.

paediatric subpopulation than adult. This value ranged from $66.2 \%( \pm 2.2)$ in the paediatric masculine subpopulation (highest value) to $49.4 \%( \pm 9.9)$ in the adult masculine subpopulation aged over 50 years (lowest value) (see Table 4). The shortening fraction (SF, \%) ranged from $44.6 \%$ in the paediatric feminine $( \pm 4.8)$ and masculine $( \pm 4.0)$ subpopulation (highest value) to $32.8 \%( \pm 7.7)$ in the adult masculine subpopulation aged over 50 years (lowest value) (see Table 4).

The other echocardiographic parameters, such as left ventricular telediastolic diameter (LVTDD, mm), the left ventricular telesystolic diameter (LVTSD, mm), the interventricular septum thickness (IVST, mm), the posterior wall thickness (PWT, mm), the left atrium (LA, mm), the right atrium (RA, mm), the aorta (mm), the right ventricle $(\mathrm{RV}, \mathrm{mm})$, the pulmonary artery pressure $(\mathrm{mmHg})$ rose from the youngest to the oldest subpopulations for both males and females (see Table 4).

The disease process was observed in both the right and the left ventricles in 56 patients (22.4\%). The right ventricle was interested in $28.6 \%$ of the paediatric feminine subpopulation (6 subjects out of 21); in 22.2\% of 
the adult feminine subpopulation aged under 50 years (10 subjects out of 45 ); in $26.7 \%$ of the adult feminine subpopulation aged over 50 years (8 subjects out of 30); in 31.1\% of the paediatric masculine subpopulation (23 subjects out of 74); in $37.2 \%$ of the adult masculine subpopulation aged under 50 years (16 subjects out of 43 ); in $257.0 \%$ of the adult masculine subpopulation aged over 50 years (10 subjects out of 37) (see Table 5).

The left ventricle' segments more interested were in decreasing order the apex, the lateral wall, the inferior and the posterior wall. Conforming to the data reported in literature, the anterior wall was affected in a lower number of cases. This finding was completely absent in the paediatric feminine subpopulation; it was observed

Table 4. Echocardiographic parameters in our population.

\begin{tabular}{|c|c|c|c|c|c|c|c|c|c|c|c|c|}
\hline & & EF (\%) & $\begin{array}{l}\text { SF } \\
(\%)\end{array}$ & $\begin{array}{c}\text { LVEDD } \\
(\mathrm{mm})\end{array}$ & $\begin{array}{c}\text { LVESD } \\
(\mathrm{mm})\end{array}$ & $\begin{array}{l}\text { TIVS } \\
(\mathrm{mm})\end{array}$ & $\begin{array}{l}\text { PWT } \\
(\mathbf{m m})\end{array}$ & $\begin{array}{c}\text { LA } \\
(\mathbf{m m})\end{array}$ & $\begin{array}{c}\text { RA } \\
(\mathbf{m m})\end{array}$ & $\begin{array}{c}\text { AO } \\
(\mathrm{mm})\end{array}$ & $\begin{array}{c}\text { RV } \\
(\mathbf{m m})\end{array}$ & $\begin{array}{c}\text { PAP } \\
(\mathrm{mmHg})\end{array}$ \\
\hline \multirow{2}{*}{$\begin{array}{c}\text { Paediatric } \\
+\end{array}$} & Mean & 65.2 & 44.6 & 43.8 & 24.0 & 8.2 & 8.2 & 25.6 & 23.9 & 25.0 & 23.0 & 22.1 \\
\hline & SD & 3.9 & 4.8 & 3.6 & 2.1 & 0.7 & 0.7 & 4.0 & 2.7 & 3.1 & 2.7 & 4.2 \\
\hline \multirow{2}{*}{$\begin{array}{c}\text { Adult } q \\
\leq \mathbf{5 0} \text { years }\end{array}$} & Mean & 62.5 & 42.3 & 48.2 & 27.7 & 9.3 & 9.2 & 29.8 & 26.9 & 29.2 & 24.8 & 30.1 \\
\hline & SD & 3.7 & 4.2 & 3.4 & 3.2 & 0.9 & 0.8 & 3.5 & 1.9 & 2.9 & 2.7 & 6.3 \\
\hline \multirow{2}{*}{ 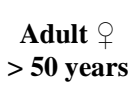 } & Mean & 54.6 & 37.6 & 50.6 & 31.7 & 10.3 & 10.1 & 34.6 & 28.9 & 32.2 & 27.2 & 34.8 \\
\hline & SD & 9.2 & 7.3 & 5.2 & 6.6 & 1.7 & 1.4 & 7.1 & 4.0 & 4.1 & 1.7 & 10.5 \\
\hline \multirow{2}{*}{$\underset{\delta}{\text { Paediatric }}$} & Mean & 66.2 & 44.6 & 48.6 & 26.8 & 8.7 & 8.6 & 28.3 & 25.9 & 28.0 & 25.0 & 25.0 \\
\hline & SD & 2.2 & 4.0 & 4.5 & 3.6 & 1.2 & 1.1 & 3.9 & 3.0 & 3.6 & 3.0 & 4.4 \\
\hline \multirow{2}{*}{$\begin{aligned} & \text { Adult } \precsim \\
\leq & 50 \text { years }\end{aligned}$} & Mean & 61.3 & 40.1 & 53.0 & 31.7 & 9.8 & 9.8 & 34.4 & 29.2 & 32.9 & 28.0 & 28.9 \\
\hline & $\mathrm{SD}$ & 6.8 & 6.1 & 3.8 & 4.9 & 1.1 & 1.0 & 3.9 & 2.4 & 2.7 & 2.9 & 5.1 \\
\hline \multirow{2}{*}{$\begin{array}{c}\text { Adult } \hat{\delta} \\
>50 \text { years }\end{array}$} & Mean & 49.4 & 32.8 & 56.1 & 37.8 & 11.3 & 10.6 & 38.8 & 32.0 & 34.4 & 29.5 & 34.7 \\
\hline & SD & 9.9 & 7.7 & 6.3 & 8.0 & 2.8 & 1.4 & 5.8 & 3.8 & 2.8 & 2.6 & 7.5 \\
\hline
\end{tabular}

EF, Ejection Fraction; SF, Shortening Fraction; LVEDD, Left Ventricular End-Diastolic Diameter; LVESD, Left Ventricular End-Systolic Diameter; TIVS, Thickness of InterVentricular Septum; PWT, Posterior Wall Thickness; LA, Left Atrium; RA, Right Atrium; AO, AOrta; RV, Right Ventricle; PAP, Pulmonary Artery Pressure.

Table 5. Presence of non-compacted areas in the right and in the left ventricle.

\begin{tabular}{|c|c|c|}
\hline & $\mathbf{R V}$ & $\mathbf{L V}$ \\
\hline Paediatric $q$ (N 21) & 6 & 21 \\
\hline$\%$ & 28.6 & 100.0 \\
\hline Adult $q \leq \mathbf{5 0}$ years $(\mathrm{N} 45)$ & 10 & 40 \\
\hline$\%$ & 22.2 & 88.9 \\
\hline Adult $q>\mathbf{5 0}$ years $(\mathbf{N}$ 30) & 8 & 23 \\
\hline$\%$ & 26.7 & 76.7 \\
\hline Paediatric $\partial^{\lambda}$ (N 74) & 23 & 74 \\
\hline$\%$ & 31.1 & 100.0 \\
\hline Adult $\hat{\jmath} \leq \mathbf{5 0}$ years $(\mathbf{N}$ 43) & 16 & 40 \\
\hline$\%$ & 37.2 & 93.0 \\
\hline Adult $\widehat{\jmath}>\mathbf{5 0}$ years $(\mathrm{N}$ 37) & 10 & 35 \\
\hline$\%$ & 27.0 & 94.6 \\
\hline
\end{tabular}

N, Number of Subjects; RV, Right Ventricle; LV, Left Ventricle. 


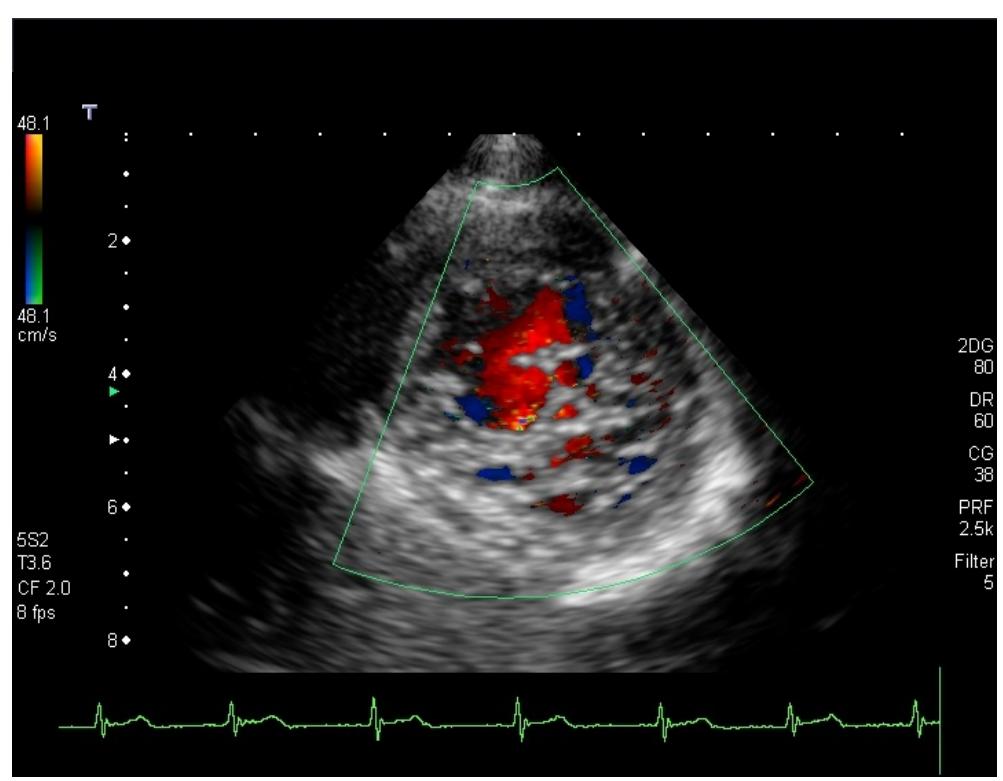

Figure 4. Apical short axis: Note the passage of blood flow between the trabeculae.

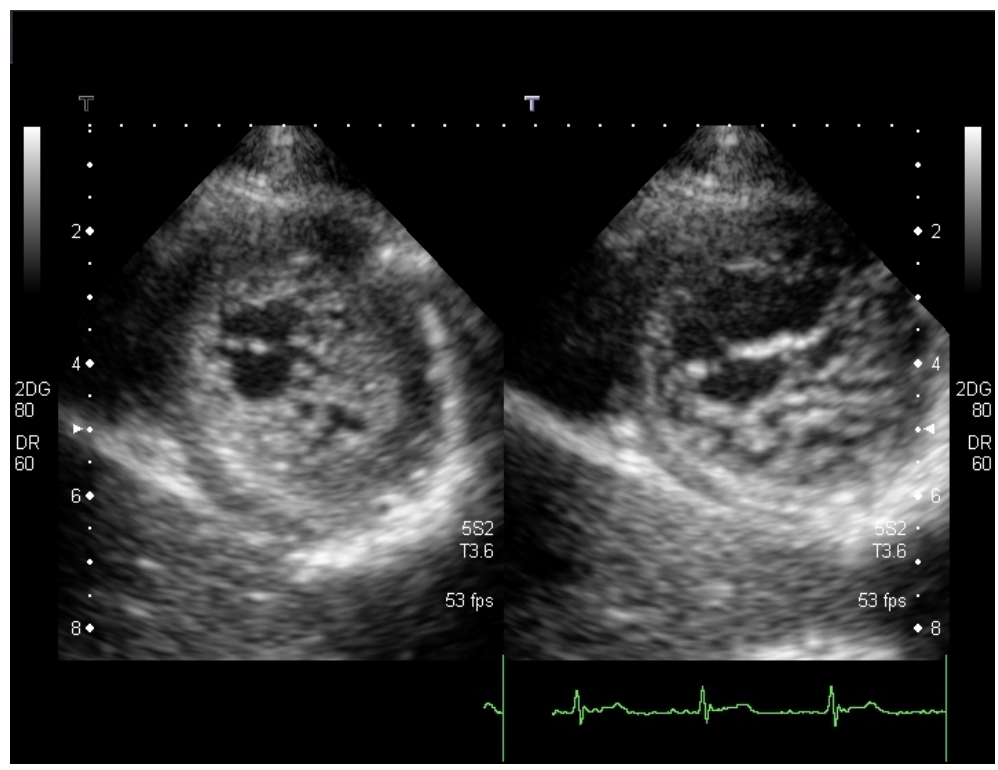

Figure 5. Apical short axis, diastole and systole.

in $26.7 \%$ of the adult feminine subpopulation aged under 50 years (12 subjects out of 45 ) and in $3.3 \%$ of the adult feminine subpopulation aged over 50 years ( 1 subjects out of 30 ), in $6.8 \%$ of the paediatric masculine subpopulation ( 5 subjects out of 74); in $7.0 \%$ of the adult masculine subpopulation aged under 50 years ( 3 subjects out of 43 ); in $5.4 \%$ of the adult masculine subpopulation aged over 50 years (2 subjects out of 37) (see Table 6).

Aberrant tendinous chords were present in $61.9 \%$ of the paediatric feminine subpopulation (13 subjects out of 21); in $55.6 \%$ of the adult feminine subpopulation aged under 50 years ( 25 subjects out of 45 ); in $43.3 \%$ of the adult feminine subpopulation aged over 50 years (13 subjects out of 30); in $74.3 \%$ of the paediatric masculine subpopulation (55 subjects out of 74); in $62.8 \%$ of the adult masculine subpopulation aged under 50 years (27 subjects out of 43); in $64.9 \%$ of the adult masculine subpopulation aged over 50 years (24 subjects out of 37) (see Table 6). 


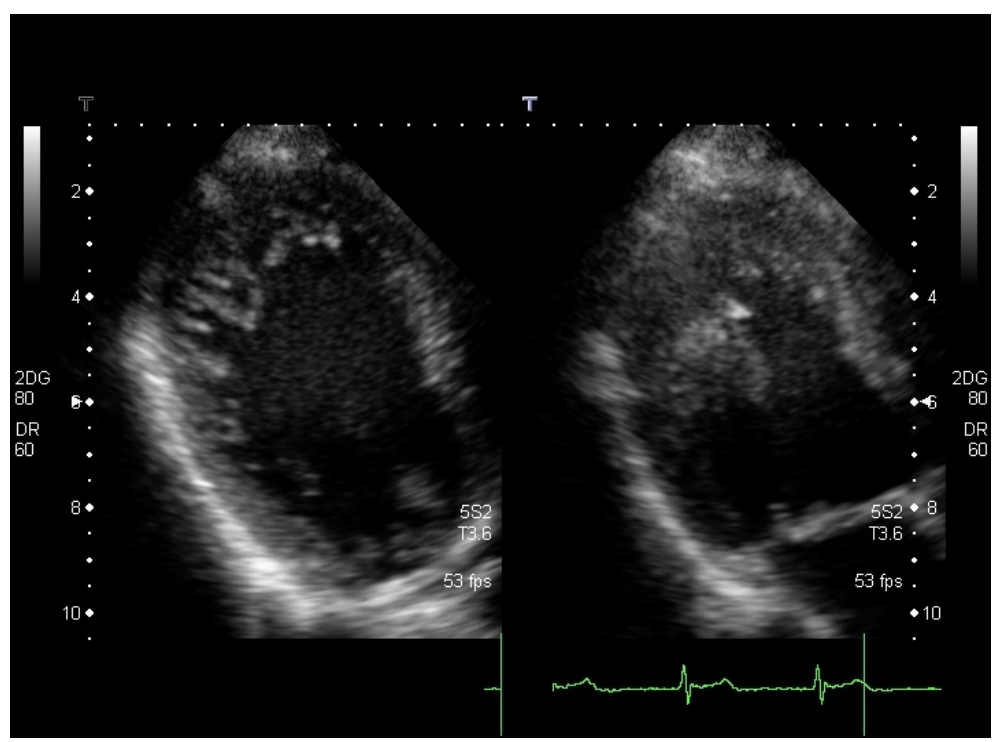

Figure 6. Two-chamber long axis view, diastole and systole.

Table 6. Segments of the right ventricle affected by LVNC.

\begin{tabular}{|c|c|c|c|c|c|c|}
\hline & LA & IW & $\mathbf{L W}$ & PW & AW & ACT \\
\hline Paediatric $q$ (N 21) & 21 & 11 & 10 & 6 & 0 & 13 \\
\hline$\%$ & 100.0 & 52.4 & 47.6 & 28.6 & 0.0 & 61.9 \\
\hline Adult $q \leq \mathbf{5 0}$ years $(\mathbf{N} 45)$ & 40 & 7 & 17 & 7 & 12 & 25 \\
\hline$\%$ & 88.9 & 15.6 & 37.8 & 15.6 & 26.7 & 55.6 \\
\hline Adult $q>\mathbf{5 0}$ years $(\mathbf{N} 30)$ & 23 & 7 & 3 & 2 & 1 & 13 \\
\hline$\%$ & 76.7 & 23.3 & 10.0 & 6.7 & 3.3 & 43.3 \\
\hline Paediatric $\precsim$ (N 74) & 72 & 40 & 38 & 26 & 5 & 55 \\
\hline$\%$ & 97.3 & 54.1 & 51.4 & 35.1 & 6.8 & 74.3 \\
\hline Adult $\precsim \leq 50$ years $(\mathrm{N} 43)$ & 38 & 16 & 19 & 9 & 3 & 27 \\
\hline$\%$ & 88.4 & 37.2 & 44.2 & 20.9 & 7.0 & 62.8 \\
\hline Adult $\delta>50$ years $(\mathrm{N} 37)$ & 35 & 14 & 14 & 4 & 2 & 24 \\
\hline$\%$ & 94.6 & 37.8 & 37.8 & 10.8 & 5.4 & 64.9 \\
\hline
\end{tabular}

LA, Left Apex; IW, Inferior Wall; LW, Lateral Wall; PW, Posterior Wall; AW, Anterior Wall; ACT, Aberrant Choardae Tendineae.

\subsection{Electrocardiographic Findings}

A high prevalence of the resting ECG abnormalities in affected subjects was noted (80.2\%), but findings are non-specific. The most prominent feature in the study population was T wave abnormalities (61.2\%). Arrhythmias are present at a rate of $59.6 \%$. In 53.6 percent of the cases it was left arrhythmias. Other patterns included pathological P waves (42.4\%), ventricular tachycardia (15.2\%), QRS abnormalities (9.6\%), left and right brunch block ( $4.4 \%$ and $0.4 \%$ respectively), atrial fibrillation ( $0.8 \%)$, and Wolff-Parkinson-White syndrome $(0.4 \%)$ (see Table 2).

The most prominent finding in the paediatric feminine subpopulation was $\mathrm{T}$ wave abnormalities $(52.4 \%, 11$ subjects out of 21); in the adult feminine subpopulation aged under 50 years arrhythmias was prevalent (51.1\%, 23 subjects out of 45); arrhythmias accounted for the more frequent finding also in the adult feminine subpopulation aged over 50 years (56.7\%, 17 subjects out of 30 ). 
The most prominent finding in the paediatric masculine subpopulation was $\mathrm{T}$ wave abnormalities $(70.3 \%, 52$ subjects out of 74$)$; in the adult masculine subpopulation aged under 50 years arrhythmias was prevalent $(72.1 \%$, 31 subjects out of 43); arrhythmias accounted for the more frequent finding also in the adult masculine subpopulation aged over 50 years (81.1\%, 30 subjects out of 37) (see Table 7).

\subsection{Associated Pathologies}

Coronary artery disease (CAD) was absent in the paediatric feminine subpopulation; it was present in $4.4 \%$ of the adult feminine subpopulation aged under 50 years (2 subjects out of 45); in 16.7\% of the adult feminine subpopulation aged over 50 years ( 5 subjects out of 30); in $1.4 \%$ of the paediatric masculine subpopulation (1 subjects out of 74); in 9.3\% of the adult masculine subpopulation aged under 50 years (4 subjects out of 43); in $59.5 \%$ of the adult masculine subpopulation aged over 50 years (22 subjects out of 37) (see Table 8).

\section{Discussion}

LVNC is defined by the presence of prominent trabeculations on the luminal surface of the ventricle in associa-

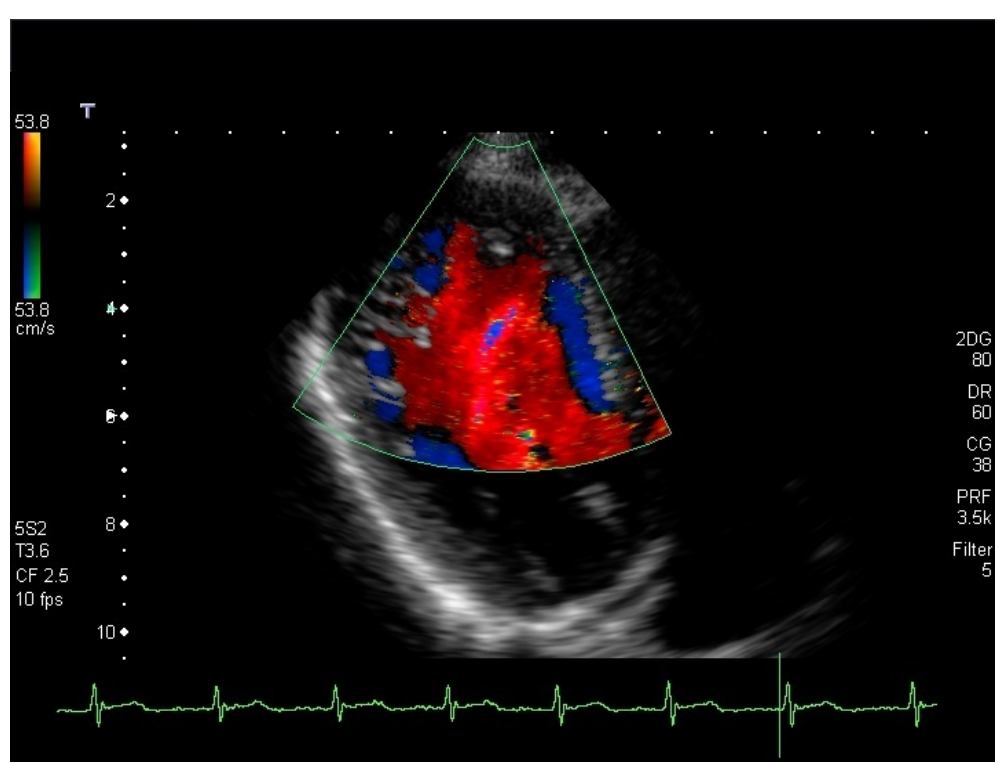

Figure 7. Two-chamber long axis view, passage of the inter-trabecular flow.

Table 7. ECG findings.

\begin{tabular}{|c|c|c|c|c|c|c|c|c|c|c|c|}
\hline & $\begin{array}{c}\text { ECG } \\
\text { Abn }\end{array}$ & $\mathbf{P}$ & QRS & $\mathbf{T}$ & LBBB & RBBB & WPW & AR & LAR & VT & AF \\
\hline Paediatric & $66.7 \%$ & $42.9 \%$ & $0.0 \%$ & $52.4 \%$ & $0.0 \%$ & $0.0 \%$ & $0.0 \%$ & $42.9 \%$ & $42.9 \%$ & $0.0 \%$ & $0.0 \%$ \\
\hline $\begin{array}{c}\text { Adult } \stackrel{?}{ } \\
\leq \mathbf{5 0} \text { years }\end{array}$ & $68.9 \%$ & $35.6 \%$ & $0.0 \%$ & $46.7 \%$ & $2.2 \%$ & $0.0 \%$ & $0.0 \%$ & $51.1 \%$ & $48.9 \%$ & $4.4 \%$ & $0.0 \%$ \\
\hline $\begin{array}{c}\text { Adult } \stackrel{\odot}{+} \\
>\mathbf{5 0} \text { years }\end{array}$ & $76.7 \%$ & $43.3 \%$ & $16.7 \%$ & $53.3 \%$ & $6.7 \%$ & $3.3 \%$ & $0.0 \%$ & $56.7 \%$ & $50.0 \%$ & $6.7 \%$ & $0.0 \%$ \\
\hline$\underset{\delta}{\text { Paediatric }}$ & $87.8 \%$ & $43.2 \%$ & $4.1 \%$ & $70.3 \%$ & $1.4 \%$ & $0.0 \%$ & $0.0 \%$ & $52.7 \%$ & $50.0 \%$ & $6.8 \%$ & $0.0 \%$ \\
\hline $\begin{array}{c}\text { Adult }{ }^{\lambda} \\
\leq 50 \text { years }\end{array}$ & $83.7 \%$ & $34.9 \%$ & $9.3 \%$ & $62.8 \%$ & $0.0 \%$ & $0.0 \%$ & $2.3 \%$ & $72.1 \%$ & $67.4 \%$ & $23.3 \%$ & $2.3 \%$ \\
\hline $\begin{array}{c}\text { Adult } \widehat{\partial} \\
>50 \text { years }\end{array}$ & $89.2 \%$ & $56.8 \%$ & $32.4 \%$ & $70.3 \%$ & $18.9 \%$ & $0.0 \%$ & $0.0 \%$ & $81.1 \%$ & $59.9 \%$ & $51.4 \%$ & $2.7 \%$ \\
\hline
\end{tabular}

ECG Abn, ECG Abnormalities; P, P wave; T, T wave; LBBB, Left Bundle Branch Block; RBBB, Right Bundle Branch Block; WPW, Wolff-Parkinson-White Syndrome; AR, Arrhythmias; LAR, Left Arrhythmias; VT, Ventricular Tachycardia; AF, Atrial Fibrillation. 
Table 8. Associated diseases.

\begin{tabular}{|c|c|c|c|c|c|c|c|c|c|c|c|c|}
\hline & ASD & CAF & PDA & BAV & HCM & DCM & CAD & D & PE & BS & $\mathbf{S}$ & MVP \\
\hline $\begin{array}{c}\text { Paediatric } \\
q\end{array}$ & $19.0 \%$ & $0.0 \%$ & $0.0 \%$ & $4.8 \%$ & $0.0 \%$ & $0.0 \%$ & $0.0 \%$ & $0.0 \%$ & $0.0 \%$ & $0.0 \%$ & $0.0 \%$ & $4.8 \%$ \\
\hline $\begin{array}{c}\text { Adult } \stackrel{+}{\leq} \\
\leq \mathbf{5 0} \text { years }\end{array}$ & $8.9 \%$ & $2.2 \%$ & $0.0 \%$ & $2.2 \%$ & $6.7 \%$ & $4.4 \%$ & $4.4 \%$ & $8.9 \%$ & $4.4 \%$ & $0.0 \%$ & $0.0 \%$ & $4.4 \%$ \\
\hline 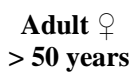 & $10.0 \%$ & $0.0 \%$ & $0.0 \%$ & $0.0 \%$ & $30.0 \%$ & $13.3 \%$ & 16.7 & $6.7 \%$ & $3.3 \%$ & $0.0 \%$ & $3.3 \%$ & $6.7 \%$ \\
\hline$\underset{\delta}{\text { Paediatric }}$ & $13.5 \%$ & $0.0 \%$ & $1.4 \%$ & $2.7 \%$ & $5.4 \%$ & $5.4 \%$ & $1.4 \%$ & $0.0 \%$ & $0.0 \%$ & $1.4 \%$ & $0.0 \%$ & $4.1 \%$ \\
\hline $\begin{array}{c}\text { Adult } \widehat{\delta} \\
\leq \mathbf{5 0} \text { years }\end{array}$ & $9.3 \%$ & $0.0 \%$ & $2.3 \%$ & $0.0 \%$ & $23.3 \%$ & $18.6 \%$ & $9.3 \%$ & $0.0 \%$ & $2.3 \%$ & $2.3 \%$ & $4.7 \%$ & $16.3 \%$ \\
\hline $\begin{array}{c}\text { Adult } \delta \\
>\mathbf{5 0} \text { years }\end{array}$ & $13.5 \%$ & $0.0 \%$ & $0.0 \%$ & $0.0 \%$ & $59.5 \%$ & $45.9 \%$ & 59.5 & $2.7 \%$ & $5.4 \%$ & $0.0 \%$ & $0.0 \%$ & $8.1 \%$ \\
\hline
\end{tabular}

ASD, Atrial Septal Defect; CAF, Coronary Artery Fistula; PDA, Patency of the Ductus Arteriosus; BAV, Bicuspid Aortic Valve; HCM, Hypertrophic CardioMyopathy; DCM, Dilated CardioMyopathy; CAD, Coronary Artery Disease; D, Dysthyroidism; PE, Pericardial Effusion; BS, Brugada Syndrome; S, Splenomegaly; MVP, Mitral Valve Prolapse.

tion with deep recesses that extend into the ventricular wall but which do not communicate with the coronary circulation. Histologically, the findings in LVNC are non-specific, with areas of normal myocardium and fibrosis. In some cases, LVNC occurs in association with other congenital heart defects, including atrial and ventricular septal defects, congenital aortic stenosis, and aortic coarctaction; when no other congenital heart lesion is present, LVNC is said to be isolated. Until recently, isolated LVNC was thought to be extremely rare with a prevalence in adults of $<0.3 \%$ [2] [4] [9], and an annual incidence in children of $<0.1$ per 100,000 [10] [11]. However, the exponential rise in the number of reports of patients with LVNC suggests that an increased awareness and the use of modern ultrasound technology have resulted in an increased detection of the morphological features of LVNC in routine clinical practice.

Our observational study is based on the largest population to date and shed new light on the clinical and morphological spectrum of this disorder.

\subsection{Clinical Presentation}

In our population the percentage of male affected by LVNC was $61.6 \%$. Little is known about the reasons of the gender differences in the prevalence of LVNC. Generally, LVNC is found more often in males than in females. On the contrary, if LVNC occurs in females, it is more extensive [12].

At the presentation, the most common reasons for referral were left ventricular systolic dysfunction (36.8\%) and uncertain electrocardiographic findings.

Congestive heart failure was noted in $7.6 \%$ of the patients. This percentage differs significantly from those reported in other observational studies. Chin et al. have reported a rate of 63\% [1], while Ritter et al. 53\% [4]. Ichida et al. found a value of 30\% [3], Oechslin et al. 68\% [2] and Stöllberger et al. 73\% [10]. We believe that the prevalence of congestive heart failure among subjects with LVNC is contained in the case of early diagnosis. Less common presentations included systemic embolism (3.2\%), pulmonary embolism (2.4\%), and ventricular thrombi (1.2\%).

The BMI was low in younger age groups, while among adults it fell within the normal range. Based on this observation we can assume that there is a relationship between body mass and noncompaction, and that this link is to be placed in some stage of embryogenesis. In our view, it would be interesting to put our patients in body composition assessment in order to quantify the Fat Mass (FM) and the Fat Free Mass (FFM) percentage.

Blood pressure was normal in the younger age groups, but it increased progressively with advancing age. This distribution of Blood Pressure may be completely independent of coexisting cardiomyopathy, but it can be attributed to chronic degenerative processes such as atherosclerosis.

Facial anomalies, such as as hypertelorism, ptosis and low-set ears, welled neck, were more frequent in children compared to adults. This observation could confirm the hypothesis that the paediatric form of LVNC is linked to different genetic defects respect the adult form. Probably the most serious forms of this cardiomyopathy are diagnosed earlier and this justifies the simultaneous presence of facial abnormalities and neuromuscular 
disorders in paediatric patients.

LVNC is associated with neuromuscular disorders such as dystrophinopathies, dystrobrevinopathies, myotonic dystrophy, zaspopathies, myoadenylatedeaminase deficiency, Charcot-Marie-Tooth disease, mitochondrial disorder, Barth syndrome, Friedrich ataxia or Pompe's disease [14]-[16]. In our study population neuromuscular disorders were present in 36 subjects on 250 (14.4\%), and were more prevalent in the paediatric subpopulation (20.8\%) respect the adult one (10.4\%). The patients were seen by a neurologist and the diagnosis was posed on the base of clinical and instrumental examination.

\subsection{Electrocardiographic Changes and Arrhythmias}

Left branch block was found more frequently in our adult population respect the paediatric one, conforming data reported in literature [4]. This difference between the paediatric and adult cases suggests that the ventricular conduction abnormality may develop later in life and could be due to progressive endocardial fibrosis in LVNC.

High prevalence of arrhythmias can be justified by the failed regression of developmental embryologic atrioventricular anatomical and electrical continuity attributable to abnormal embryologic persistence of atrioventricular muscular continuity.

\subsection{Echocardiographic Findings}

The diagnosis of LVNC was placed in the presence of the most widely used echocardiographic criteria (Jenni et al., Stöllberger et al., Chin et al.). 52 subjects fulfilled at the same time all three criteria.

The characteristics of our patients responded to most of the criteria proposed by Jenni with the exception of the absence of Congenital Heart Disease (CHD). It is clear that patients with LVNC may also manifest coexistent congenital heart lesions, as was seen among several patients in our study cohort. The presence of CHD does not exclude the diagnosis of LVNC.

Structural abnormality related to the non-compacted myocardium involves in some cases the presence of mild mitral or tricuspid insufficiency. This condition can be paraphysiological in athletes. In this regard it is good to specify that $9.6 \%$ of our study-population (24 subjects out of 250 ) was composed of athletes send to our attention by sport physicians of the area for an echocardiographic evaluation in order to clarify the nature of physical examination and/or electrocardiogram abnormalities.

Depressed left ventricular function may be absent at the time of presentation (158 patients on 250, 63.2\%), or may be clinically overt since childhood (1 patient in our series).

The EF was equal to $61.0 \pm 8.9$ in the general population, while the SF was $41.0 \pm 6.9$. The first data, progressively decreasing with age, differed substantially from those reported in the literature (recurring values 25 30 for the ejection fraction). This finding may be justified considering that in most cases reported in our series the diagnosis was given early. We hypothesize that the cardiac function tends to worsen from the onset of the disease (asymptomatic stage) until its last evolution (heart failure).

The left ventricular telediastolic diameter (LVTDD, mm), the left ventricular telesystolic diameter (LVTSD, $\mathrm{mm}$ ), the interventricular septum thickness (IVST, mm), the posterior wall thickness (PWT, mm), the left atrium (LA, mm), the right atrium (RA, mm), the aorta $(\mathrm{mm})$, the right ventricle (RV, $\mathrm{mm}$ ), the pulmonary artery pressure (mmHg) rose from the youngest to the oldest subpopulations for both males and females. This finding suggests that, progressing the disease to its final form, there may be a structural heart change. In particular, the thickening of the posterior wall and of the septum was due to an increase of non-compacted layer. The cardiac walls, thus changed, would not be able to maintain normal blood pressure resulting in dilatation of the heart chambers.

Regarding the distribution of trabeculation, the most frequently involved segments were apical followed by the lateral and the inferior mid-segments (respectively $91.6 \%, 40.4 \%$ and $38.0 \%$ of the total population). These data are consistent with those reported in the literature.

Isolated LVNC was seen in 101 cases and rest of the cases (40.4\%) had associated diseases diagnosed by echocardiography. Of these $19.2 \%$ had hypertrophic cardiomyopathy, $13.6 \%$ dilated cardiomyopathy, $13.6 \%$ coronary artery disease, $12.0 \%$ atrial septal defects, $7.2 \%$ mitral valve prolapse, $2.8 \%$ dysthyroidism, $2.4 \%$ pericardial effusion, and $1.6 \%$ bicuspid aortic valve.

Splenomegaly, patent ductus of Botallo, Brugada syndrome and coronary fistulae were also present with percentage of 1.2, $0.8,0.8$ and 0.4 respectively. Based on this finding, we agree that there are two forms of myocar- 
dial noncompaction: isolated and non-isolated myocardial non-compaction. Non-isolated myocardial non-compactions are occasionally reported postnatally in association with congenital heart anomalies such as ventricular septal defects, pulmonic stenosis and atrial septal defects.

Although coronary artery diseases may be present since childhood (1 patient in our series), they are prevalent in the adulthood.

\subsection{Therapy and Follow-Up}

It was provided a follow-up with echocardiographic controls every six months, Holter recording and exercise test every year.

The $40.0 \%$ of patients (100 out of 250) underwent NMR, which confirmed the diagnosis of LVNC. One of the patients had areas of fibrosis [17].

Two of the subjects examined presented, consequently to a feverish episode, an ECG tracing suggestive of Brugada syndrome and they were immediately considered for a flecainide provocative test. One of them received an implantable defibrillator.

Low-dose ASA with gastric protection therapy was prescribed to the patients above 30 years. One patient, intolerant to beta-blockers and ACE-inhibitors, was treated with sartani because of depressed EF and he had a sensible improvement.

Ongoing follow-up one patient worsened with an increase of non-compacted areas.

\section{Conclusions}

Left ventricular non-compaction can be easily diagnosed by echocardiography if the echocardiographer is familiar with this congenital disorder and if clear cut diagnostic criteria are used. However, because of its low prevalence and awareness deficits in the medical community, non-compaction cardiomyopathy probably is diagnosed too late and not frequently enough.

This study demonstrates the increased detection of patients fulfilling echocardiographic criteria of LVNC and its association with other disorders. It also shows that milder phenotypes exist and the disease is detected incidentally in some cases.

It is essential not to miss the findings of noncompaction, as the condition may lead to serious heart failure, thromboembolic events, ventricular tachyarrhythmia or death. Early recognition of noncompaction may give better follow-up and management of patients with this condition.

In view of the possible association with neuromuscular disorders we consider the importance of an early neurological videat in patients with LVNC.

\section{Acknowledgements}

The authors wish to sincerely tank Dr. Gianfranco Trionfera, CEO of the Valmontone Hospital, for making it possible to carry out this research.

\section{References}

[1] Chin, T.K., Perloff, J.K., Williams, R.G., Jue, K. and Mohrmann, R. (1990) Isolated Noncompaction of Left Ventricular Myocardium: A Study of Eight Cases. Circulation, 82, 507-513. http://dx.doi.org/10.1161/01.CIR.82.2.507

[2] Oechslin, E.N., Attenhofer Jost, C.H., Rojas, J.R., Kaugmann, P.A. and Jenni, R. (2000) Long-Term Follow-Up of 34 Adults with Isolated Left Ventricular Noncompaction: A Distinct Cardiomyopathy with Poor Prognosis. Journal of the American College of Cardiology, 36, 493-500. http://dx.doi.org/10.1016/S0735-1097(00)00755-5

[3] Ichida, F., Hamamichi, Y., Miyawaki, T., Ono, Y., Kamiya, T., Akagi, T., Hamada, H., Hirose, O., Isobe, T., Yamada, K., Kurotobi, S., Mito, H., Miyake, T., Murakami, Y., Nishi, T., Shinohara, M., Seguchi, M., Tashiro, S. and Tominatsu, H. (1999) Clinical Features of Iisolated Isolated Noncompaction of the Ventricular Myocardium: Long-Term Clinical Course, Hemodynamic Properties, and Genetic Background. Journal of the American College of Cardiology, 34, 233240. http://dx.doi.org/10.1016/S0735-1097(99)00170-9

[4] Ritter, M., Oechslin, E., Sütsch, G., Attenhofer, C., Schneider, J. and Jenni, R. (1997) Isolated Noncompaction of the Myocardium in Adults. Mayo Clinic Proceedings, 72, 26-31. http://dx.doi.org/10.4065/72.1.26

[5] Shah, C.P., Nagi, K.S., Thakur, R.K., Boughner, D.R. and Xie, B. (1998) Spongy Left Ventricular Myocardium in Adults. Texas Heart Institute Journal, 25, 150-151. 
[6] Udeoji, D.U., Philip, K.J., Morrissey, R.P., Phan, A. and Schwarz, E.R. (2013) Left Ventricular Noncompaction Cardiomyopathy: Updated Review. Therapeutic Advances in Cardiovascular Disease, 7, 260-273. http://dx.doi.org/10.1177/1753944713504639

[7] Jenni, R., Oechslin, E., Schneider, J., Attenhofer Jost, C. and Kaufmann, P.A. (2001) Echocardiographic and Pathoanatomic Characteristics of Isolated Left Ventricular Noncompaction: A Step Toward Classification as a Distinct Cardiomyopathy. Heart, 86, 666-671. http://dx.doi.org/10.1136/heart.86.6.666

[8] Jenni, R., Oechslin, E.N. and van der Loo, B. (2007) Isolated Ventricular Non-Compaction of the Myocardium in Adults. Heart, 93, 11-15. http://dx.doi.org/10.1136/hrt.2005.082271

[9] Stöllberger, C., Finsterer, J. and Blazek, G. (2001) Prognosis of Left Ventricular Hypertrabeculation/Noncompaction and Association with Additional Cardiac Abnormalities and Neuromuscolar Neuromuscular Comorbidity. American Journal of Cardiology, 90, 899-902. http://dx.doi.org/10.1016/S0002-9149(02)02723-6

[10] Lang, R.M., Bierig, M., Devereux, R.B., Flachskampf, F.A., Foster, E., Pellikka, P.A., Picard, M.H., Roman, M.J., Seward, J., Shanewise, J.S., Solomon, S.D., Spencer, K.T., Sutton, M.S. and Stewart, W.J. (2005) Recommendations for Chamber Quantification: A Report from the American Society of Echocardiography's Guidelines and Standards Committee and the Chamber Quantification Writing Group, Developed in Conjunction with the European Association of Echocardiography, a Branch of the European Society of Cardiology. Journal of the American Society of Echocardiography, 18, 1440-1463. http://dx.doi.org/10.1016/j.echo.2005.10.005

[11] Stöllberger, C., Finsterer, J. and Blazek, G. (2002) Left Ventricular Hypertrabeculation, Noncompaction and Association with Additional Cardiac Abnormalities and Neuromuscular Disorders. American Journal of Cardiology, 90, 899902. http://dx.doi.org/10.1016/S0002-9149(02)02723-6

[12] World Health Organization (2006) Obesity and Overweight. Fact Sheet Number 311. World Health Organization, Geneva.

[13] Mancia, G., Fagard, R., Narkiewicz, K., Redón, J., Zanchetti, A., Böhm, M., Christiaens, T., Cifkova, R., De Backer, G., Dominiczak, A., Galderisi, M., Grobbee, D.E., Jaarsma, T., Kirchhof, P., Kjeldsen, S.E., Laurent, S., Manolis, A.J., Nilsson, P.M., Ruilope, L.M., Schmieder, R.E., Sirnes, P.A., Sleight, P., Viigimaa, M., Waeber, B. and Zannad, F., Task Force Members (2013) 2013 ESH/ESC Guidelines for the Management of Arterial Hypertension: The Task Force for the Management of Arterial Hypertension of the European Society of Hypertension (ESH) and of European Society of Cardiology (ESC). Journal of Hypertension, 31, 1281-1357. http://dx.doi.org/10.1097/01.hjh.0000431740.32696.cC

[14] Stöllberger, C., Blazek, G., Winkler-Dworak, M. and Finsterer, J. (2008) Sex Differences in Left Ventricular Noncompaction in Patients with and without Neuromuscular Disorders. Revista Española de Cardiología, 61, 130-136. http://dx.doi.org/10.1157/13116200

[15] Stöllberger, C., Finsterer, J. and Blazek, G. (2002) Left Ventricular Hypertrabeculation/Noncompaction and Association with Additional Cardiac Abnormalities and Neuromuscular Disorders. American Journal of Cardiology, 90, 899902. http://dx.doi.org/10.1016/S0002-9149(02)02723-6

[16] Finsterer, J., Stöllberger, C. and Blazek, G. (2006) Neuromuscular Implications in Left Ventricular Hypertrabeculation/ Noncompaction. International Journal of Cardiology, 110, 288-300. http://dx.doi.org/10.1016/j.ijcard.2005.10.028

[17] Kramer, C.M. (2010) Cardiac Magnetic Resonance Imaging Identification of Myocardial Fibrosis: The Need for Standardization and Therapies. Journal of the American College of Cardiology, 56, 288-289. http://dx.doi.org/10.1016/j.jacc.2010.01.063 